\title{
HORTA UNIVERSITÁRIA: PLANTANDO CIÊNCIA E REDUZINDO DESIGUALDADES
}

\author{
Lívia Marques BrandolT ${ }^{1}$ \\ h†tps://orcid.org/0000-0002-6614-7502 \\ Vitória Aparecida Porto Lima ${ }^{2}$ \\ https://orcid.org/0000-0002-1149-2421 \\ Josimar Rodrigues OliveIRA ${ }^{3}$ \\ https://orcid.org/0000-0002-5648-3713 \\ Flaviana Tavares Vieira Teixeira 4 \\ http://orcid.org/0000-0003-3797-1778
}

Resumo: O projeto "Horta Universitária: plantando ciência e reduzindo desigualdades" teve como objetivo criar um ambiente cada vez mais sustentável dentro da universidade, a partir da elaboração de uma horta comunitária, com a participação de estudantes de graduação dos

1 Graduanda em Fisioterapia da Universidade Federal dos Vales do Jequitinhonha e Mucuri (UFVJM) - Campus JK, Rodovia MGT 367, n. 5000 - km 583, Bairro Alto da Jacuba, Diamantina-MG, CEP 3910o-ooo. E-mail: livia.brandolt@hotmail.com.

2 Graduanda em Agronomia da Universidade Federal dos Vales do Jequitinhonha e Mucuri (UFVJM) - Campus JK, Rodovia MGT 367, n. 5000 - km 583, Bairro Alto da Jacuba, Diamantina-MG, CEP 39100-ooo. E-mail: vitoriadtna@hotmail.com.

3 Doutor e Mestre em Solos e Nutrição de Plantas pela Universidade Federal de Viçosa (UFV), Engenheiro Agrônomo formado pelo Instituto Federal de Educação, Ciência e Tecnologia de Minas Gerais (IFMG) - Campus Bambuí. Atualmente é Engenheiro Agrônomo da Universidade Federal dos Vales do Jequitinhonha e Mucuri (UFVJM) - Campus JK, Rodovia MGT 367, n. 5000 - km 583, Bairro Alto da Jacuba, Diamantina-MG, CEP 39100-ooo.E-mail: josimar.oliveira@ufvjm.edu.br, josimarodrigues@yahoo.com.br.

4 Doutora em Química Inorgânica pela Universidade Federal de Minas Gerais (UFMG), Mestre em Agroquímica pela Universidade Federal de Viçosa (UFV), Licenciada em Química e Graduada em Ciências Naturais pela Universidade Federal de São João del-Rei (UFSJ). Professora de Química do curso de Engenharia Química do Instituto de Ciência e Tecnologia da Universidade Federal dos Vales do Jequitinhonha e Mucuri (UFVJM) Campus JK, Rodovia MGT 367, n. 5000 - km 583, Bairro Alto da Jacuba, Diamantina-MG, CEP 39100-ooo.E-mail: flaviana.tavares@ufvjm.edu.br. 
diversos cursos ofertados nos Campi da Universidade Federal dos Vales do Jequitinhonha e Mucuri (UFVJM), em Diamantina, visando promover a redução da retenção e evasão. Cerca de $87,5 \%$ dos integrantes da equipe do projeto melhoraram seu Coeficiente de Rendimento Acadêmico (CRA). Portanto, podemos inferir que a abertura de uma oportunidade para que estudantes dos diversos cursos de graduação da UFVJM venham a integrar algum tipo de projeto em âmbito universitário, mesmo como voluntário, além de cumprir com o dever constitucional da universidade referente a indissociabilidade do ensino, pesquisa e extensão, torna-se uma atividade motivadora e que contribui positivamente para a manutenção ou melhoria do rendimento acadêmico. Por sua vez, a melhoria no rendimento acadêmico, elimina um possível fator que levaria a evasão desse aluno do curso ou da instituição de ensino superior. Palavras-Chave: Retenção. Evasão. Extensão. Horticultura. Comunitária.

\title{
UNIVERSITY VEGETABLE GARDEN: PLANTING SCIENCE AND REDUCING INEQUALITIES
}

\begin{abstract}
The project "University Vegetable Garden: planting science and reducing inequalities" aimed to create an increasingly sustainable environment within the university, from the elaboration of a community garden, with the participation of undergraduate students from the various courses offered in the Campuses of the Federal University of the Jequitinhonha and Mucuri Valleys (UFVJM), in Diamantina, aiming to promote the reduction of retention and evasion. Approximately $87.5 \%$ of the project team members improved their Academic Performance Coefficient (CRA). Therefore, we can infer that the opening of an opportunity for students of the various undergraduate courses of UFVJM to integrate some type of project in a university scope, even as a volunteer, in addition to complying with the constitutional duty of the University regarding the indissociability of teaching, research and extension, it becomes a motivating activity and contributes positively to the maintenance or improvement of academic achievement. In turn, the improvement in academic achievement eliminates a possible factor that would lead to the avoidance of this student of the course or institution of higher education.
\end{abstract}

Keywords: Retention. Evasion. Extension. Horticulture. Community.

\section{HUERTA UNIVERSITARIA: PLANTANDO CIENCIA Y REDUCIENDO DESIGUALDADES}

Resumen: El proyecto "Huerta Universitaria: plantando ciencia y reduciendo desigualdades" tuvo como objetivo crear un ambiente cada vez más sostenible dentro de la universidad, a partir de la elaboración de una huerta comunitaria, con la participación de estudiantes de graduación de los diversos cursos ofrecidos en los Campi de la Universidad Federal de los Valles del Jequitinhonha y Mucuri (UFVJM), en Diamantina, para promover la reducción de la retención y evasión. Cerca del 87,5 \% de los integrantes del equipo del proyecto mejoraron su Coeficiente de Rendimiento Académico (CRA). En ese sentido, podemos inferir que la apertura de una oportunidad para que estudiantes de los diversos cursos de graduación de la UFVJM vengan a integrar algún tipo de proyecto en ámbito universitario, aun como voluntario, además de cumplir con el deber constitucional de la Universidad referente a la indisociabilidad de la enseñanza, investigación y extensión, se convierte en una actividad motivadora y que contribuye positivamente al mantenimiento o mejora del rendimiento 
académico. Por su parte, la mejora en el rendimiento académico, elimina un posible factor que llevaría la evasión de ese alumno del curso o de la institución de enseñanza superior.

Palabras Clave: Retención. Evasión. Extensión. Horticultura. Comunidad.

Submetido em: 16/12/2018

Aceito em: 20/12/2019

\section{INTRODUÇÃO}

A horticultura é uma atividade de grande importância econômica no Brasil. Especialmente no Vale do Jequitinhonha, essa atividade se destaca como uma das principais desenvolvidas por agricultores familiares. Sua relevância representa uma melhora na qualidade de vida das pessoas em termos nutricionais, economia das famílias, melhora e/ou manutenção da saúde e prevenção de doenças. No entanto, a horticultura, além de ser uma atividade agrícola economicamente relevante pode ser utilizada com objetivos para além da simples produção e comercialização de alimentos. Fernandes (2011) destaca que uma horta pode contribuir para a promoção de ações educacionais e ser utilizada como terapia ocupacional, podendo reduzir os índices de depressão, além de ser fonte de alimentos e renda.

Nesse sentido, a criação de uma horta didática, seja em escolas do ensino fundamental e médio, bem como nas instituições de ensino superior públicas, pode ser um caminho para oportunizar a inserção de estudantes em projetos ao longo de sua vida acadêmica, gerar novos conhecimentos, bem como quebrar a rotina árdua de estudos e trabalhos acadêmicos, tornando-se uma atividade-escape que gere bem estar e motivação. Autores como Van der Horst et al. (2007) ainda destacam que as práticas alimentares de jovens são influenciadas pelo ambiente em que eles estão inseridos, assim como acontece com outros grupos populacionais. Como os estudantes estão mais preocupados em ter um bom desempenho acadêmico, participar e manter boas relações socioculturais, acabam por deixar de lado a importância de uma alimentação saudável (ALVES \& BOOG, 2007). Logo, destaca-se o ambiente universitário como um espaço que merece particular atenção, pois, muitos hábitos alimentares adquiridos pelos estudantes, em sua maioria jovens, se mantêm na idade adulta, representando um momento singular para a promoção da alimentação saudável (HABERMAN \& LUFFEY,1998 ). 
No Brasil, existem hortas comunitárias em algumas universidades, como por exemplo, na Universidade de São Paulo (USP), onde o principal objetivo no âmbito de saúde pública foi construir um ambiente para discutir a sustentabilidade e alimentação saudável (HORTA FSP-USP, 2017). Esses espaços, também são ótimos para a realização de cursos, oficinas e demais ações de caráter extensionistas para alcançar a sociedade local, visando promover a educação ambiental e educação alimentar, podendo estabelecer uma fusão entre o ser humano e a natureza. Uma das principais vantagens na utilização de uma horta para tais ações é a interdisciplinaridade, onde é possível envolver pessoas de diferentes áreas, despertando a reflexão social, levando o ser humano a mudar hábitos e atitudes com relação ao ambiente (CRIBB, 2010) e a sua saúde alimentar e nutricional. Nas universidades, o envolvimento dos estudantes de diferentes cursos em projetos relacionados a implantação e condução de uma horta pode contribuir para um aumento do rendimento acadêmico, estimular a melhoria dos seus hábitos alimentares e ser até mesmo utilizado como terapia. Muitas das vezes, os projetos relacionados à hortas comunitárias estão associados a trabalhos de extensão, o que possibilita a troca de valores, podendo reunir estudantes de diferentes cursos e o público externo, como pequenas comunidades e associações (SCHEIDEMANTEL; KLEIN; TEIXEIRA, 2004).

O ambiente universitário, nos últimos anos, passou a ser ainda mais estratégico como espaço para a promoção da alimentação saudável e da segurança alimentar e nutricional, uma vez que incorporou medidas de ação afirmativa (SOUSA \& PORTES, 2011). Pois, segundo Santos (2012), uma política efetiva de permanência do estudante que ingressa pelo sistema de cotas pressupõe, entre outros, a garantia de acesso a bolsas de permanência, a alimentação (restaurante universitário), a moradias estudantis e a livros e mídia em geral. Morgado e Santos (2008), afirmam que crianças que participam diretamente do cultivo em hortas possuem comportamento alimentar mais voltado para produtos naturais e saudáveis, o que pode favorecer a manutenção de bons hábitos durante a vida adulta. Para Moritz e Costa (2018), uma horta comunitária além de trazer o resgate e o compartilhamento de saberes, desperta também o interesse sobre a adoção de hábitos saudáveis, respeito à natureza e incentiva o espírito de trabalho coletivo entre os indivíduos que estão diretamente envolvidos nessa atividade. Dessa forma, jovens também podem ser beneficiados em questões de saúde no decorrer da vida ao estarem inseridos em projetos dessa natureza. 
A vida universitária dos estudantes pode não ser unicamente de responsabilidade do jovem, mas também da universidade que precisa contemplar a elaboração de propostas de cunho preventivo que assegurem o seu sucesso acadêmico (CUNHA \& CARILLO, 2005). Dessa forma, vemos a importância do ambiente institucional favorecer atividades de extensão voltadas para esse grupo de alunos que poderiam ser mais vulneráveis e propensos à retenção e evasão nos cursos de graduação.

Nesse sentido, o objetivo do projeto de extensão "Horta Universitária" foi criar um ambiente cada vez mais sustentável dentro da Universidade, a partir da elaboração de uma horta comunitária, com a participação de estudantes de graduação dos diversos cursos ofertados nos Campi da Universidade Federal dos Vales do Jequitinhonha e Mucuri (UFVJM), em Diamantina, visando promover a redução da retenção e evasão. O presente artigo traz um relato de experiência sobre as atividades desenvolvidas e o impacto dessas ações no desempenho acadêmico dos estudantes integrantes do projeto.

\section{METODOLOGIA}

O presente projeto de extensão foi realizado na Universidade Federal dos Vales do Jequitinhonha e Mucuri (UFVJM), no município de Diamantina-MG, desenvolvendo as ações descritas a seguir:

» Seleção dos estudantes: o processo seletivo foi realizado por meio de Edital do Programa de Educação Tutorial (PET) - Estratégias para diminuir a retenção e evasão, da UFVJM. Os critérios para integrar a equipe do projeto era estar regularmente matriculado em qualquer curso de graduação presencial dos Campi do município de Diamantina e prioritariamente apresentar coeficiente de rendimento acadêmico abaixo da média (60 pontos) e/ou reprovações ao longo do curso de graduação que estava realizando. Após o processo seletivo, os estudantes inscritos excedentes que não se enquadravam nesses critérios, mas nunca haviam participado de um projeto dentro da Universidade foram incorporados a equipe, dado a existência de vagas.

» Participação da Dinâmica de Integração: A primeira atividade realizada após a seleção foi uma dinâmica, onde os estudantes tiveram a oportunidade de apresentarem-se e interagir uns com os outros, fortalecendo 
os vínculos como integrantes de um grupo. Nessa dinâmica, a Tutora do PET Estratégias entregou aos estudantes um desenho denominado Pentáculo do Bem Estar (NAHAS; BARROS; FRANCALACCI, 2000). A dinâmica levou os estudantes a refletirem sobre cinco áreas fundamentais da sua vida: atividade física; comportamento preventivo; controle do stress; nutrição e relacionamento social. Após, a realização da dinâmica, houve um debate sobre o resultado de cada um, no sentido de estimulá-los a buscar melhorar aquela área que ficou pouco preenchida no pentáculo, buscando o bem estar pessoal pleno.

Criação de uma Horta Universitária: Realizou-se um projeto inicial para definir como seria a horta e quais os alimentos que seriam produzidos. A Horta Universitária foi montada no Setor de Olericultura do Campus JK, em área pertencente ao Departamento de Agronomia. As sementes e demais insumos necessários para a condução do projeto foram obtidos em parceria com a Divisão de Fazendas, da Pró-Reitoria de Administração. Os estudantes receberam capacitações e foram acompanhados pela tutora do PET Estratégias e pelo Engenheiro Agrônomo da Universidade, no desenvolvimento das atividades desde o plantio à colheita de cada cultura. A horta foi conduzida com manejo de base ecológica, prezando pela sustentabilidade e responsabilidade ambiental do sistema de produção.

Criação de materiais educativos: Todo material didático produzido pelo projeto foi embasado na literatura e revisado pelos coordenadores para que tivesse uma fundamentação teórica consolidada. Foram elaborados pelos estudantes do projeto uma cartilha sobre produção de mudas de hortaliças, uma história infantil intitulada "Joãozinho, o menino que adorava plantar" e mini-programas de rádio (pílulas) sobre alimentação saudável e cultivo de plantas olerícolas.

Oficinas educativas para comunidade: Foram ofertadas oficinas de capacitação tanto para a comunidade acadêmica, quanto para o público externo da Universidade, de modo a conscientizar e orientar as pessoas sobre o desenvolvimento sustentável, alimentação, saúde e até ensinamentos de como gerar renda e minimizar o custo de vida. Essas atividades foram realizadas em estande montado pela equipe do projeto no Campus I, da UFVJM, durante a terceira edição da Semana de Ciência e Tecnologia de Diamantina. 
"Autoavaliação e acompanhamento do rendimento acadêmico dos integrantes: Os estudantes fizeram uma autoavaliação no final da sua participação no projeto, refletindo sobre o seu envolvimento nas ações de extensão, a sua interação na equipe e com o público externo, bem como seu desempenho no projeto, de modo geral. Além disso, o desempenho acadêmico foi acompanhado pelos coordenadores do projeto de extensão e pela Tutora do PET Estratégias, avaliando se houve novas reprovações e se houve aumento ou redução do Coeficiente de Rendimento Acadêmico, comparando-se a situação curricular do estudante antes e depois de participar do projeto.

\section{RELATO DE EXPERIÊNCIA}

O processo seletivo realizado pelo PET Estratégias para estudantes que tivessem interesse em integrar a equipe do projeto foi divulgado amplamente por meio das mídias de comunicação institucional da Universidade, por listas de e-mails e redes sociais. Desse modo, foram selecionados oito estudantes de cinco diferentes cursos de graduação: Bacharelado em Ciência e Tecnologia (BCT); Bacharelado em Ciências Humanas (BHU), Bacharelado em Agronomia (AGRO), Bacharelado em Nutrição (NUT) e Bacharelado em Turismo (TUR), conforme Figura 1. Além desses estudantes selecionados, a equipe do projeto contava com coordenadores da área de Agronomia, Ciências Naturais e Química, bem como a Tutora do PET Estratégias que é Graduanda em Fisioterapia. Nesse sentido, o projeto veio de encontro a atender todas as diretrizes constantes na Política Nacional de Extensão Universitária, tendo em vista que houve Interação Dialógica, Interdisciplinaridade e Interprofissionalidade, Indissociabilidade Ensino-Pesquisa-Extensão, Impacto na formação do estudante e Impacto e transformação social (FORPROEX, 2012), como será visto adiante. 


\section{Figura 1-PoRCENTAGEM de ESTUdANTES De CADA CURSO de GRAduAÇÃo dos CAM- PI DA UFVJM, EM DIAMANTINA-MG, QUE INTEGRARAM O PROJETO DE EXTENSÃO.}

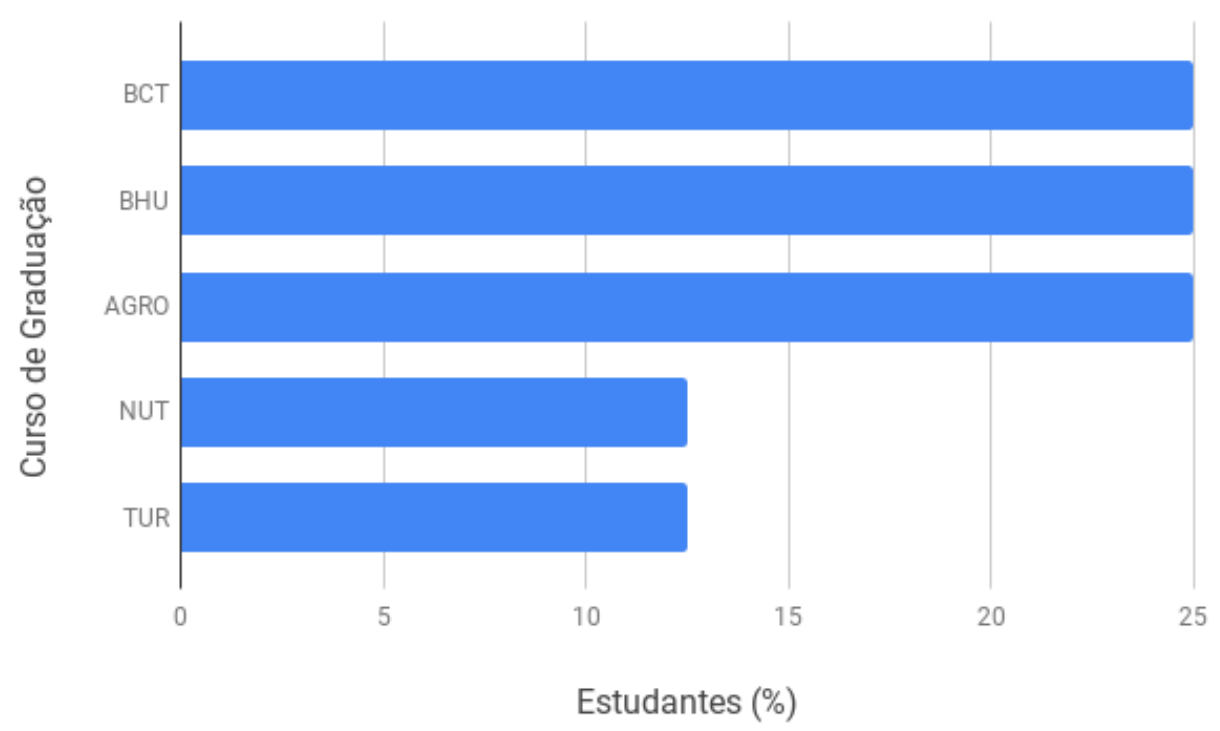

Fonte: Dados do PRojeto, 2018; BCT - Bacharelado em CIÊNCIA E TeCnolocia; BHU - BaCharelado EM CIÊNCIAS Humanas; AGRO-BACHARELAdo EM AGronomia; NUT-BACHARELAdo EM NUtrição E TUR-Bacharelado EM TURISMO.

Portanto, em termos percentuais, a Figura 1 mostra que $25 \%$ dos estudantes que integraram a equipe foram da área de Ciências Agrárias propriamente dita (AGRO), que está diretamente relacionada à temática do projeto de extensão: horticultura, $25 \%$ de estudantes das áreas de engenharias (BCT), 37,5\% da área de Ciências Humanas (BHU e TUR) e 12,5 \% da área da saúde (NUT).

A maioria dos estudantes selecionados $(87,5 \%)$ eram jovens, como mostra a Figura 2, com faixa etária variando de 18 a 25 anos. Ao realizar a dinâmica, muitos desses jovens confirmaram por meio de sua reflexão o exposto por diversos autores como Van der Horst et al. (2007), referente as influências do ambiente no qual estão inseridos sobre as cinco áreas que caracterizavam seu bem estar pleno (NAHAS; BARROS; FRANCALACCI, 2000), ou seja, as condições e as dificuldades que o ambiente universitário colocada a esse estudante, pode ser fator redutor do bem estar, desmotivacional e consequentemente levar a elevados índices de retenção e evasão. Amorim e Sabino (2017) levantaram dados relevantes relacionados à retenção e evasão nos Campi da Universidade Federal dos Vales do Jequitinhonha e Mucuri (UFVJM), em Diamantina, e observaram que os índices médios de evasão entre 2010 a 2014 
variaram de 35,1 a 62,1 \%, dependendo do curso de graduação, enquanto o percentual de alunos reprovados por nota em todas as disciplinas apresentou índices variando de 54 a $67 \%$, no mesmo período.

FIGURA 2-FAIXA ETÁRIA DOS ESTUDANTES QUE INTEGRARAM O PROJETO DE EXTENSÃO, DiAMANTINA-MG.
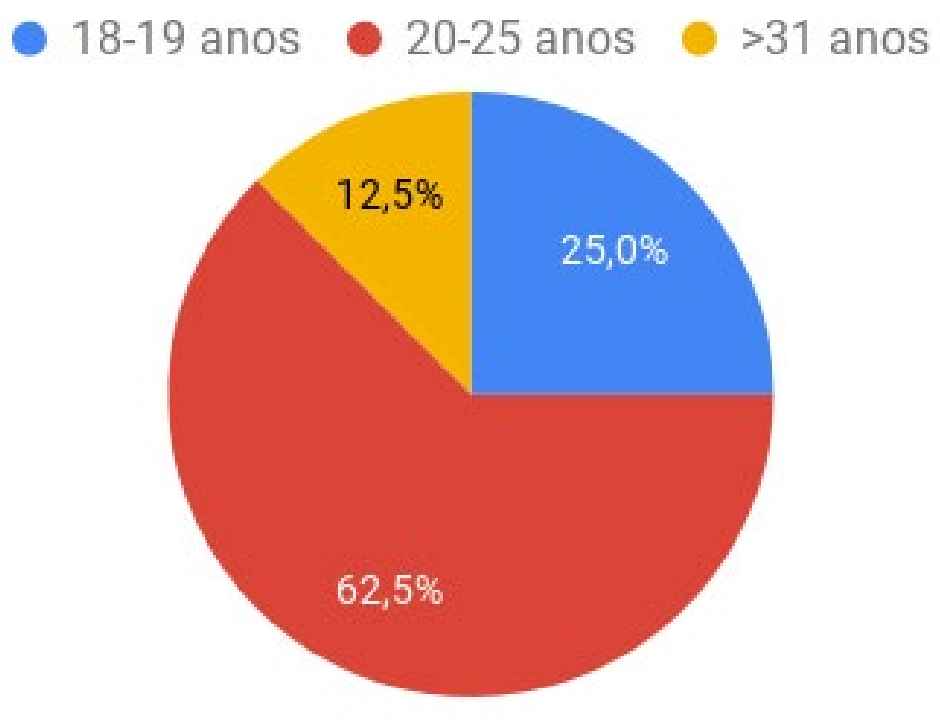

FONTE: DADOS DO PROJETO, 2018.

$\mathrm{Na}$ autoavaliação, ao serem questionados sobre a motivação que levou cada estudante a se inscrever inicialmente para participarem do projeto, foram citados inúmeros motivos diferentes, entre eles a oportunidade de obter "novas experiências", "aprendizado e trabalho em equipe", "horas extracurriculares", "aprender sobre horta", "descanso mental”, "aprender e compartilhar conhecimento", "fazer novas amizades", obter "conhecimento diversificado", "relação com o curso de origem" e "por gostar de trabalhar com plantas".

Apesar da divergência de respostas apresentadas pelos estudantes, as palavras "novas experiências" e "trabalho em equipe", foram citadas repetidamente em cerca de 33 \% das autoavaliação, mostrando que essas eram motivações similares que aqueles estudantes buscavam ao ingressar no projeto de extensão.

A efetiva participação dos estudantes nas atividades de implantação e condução da horta, propriamente dita, foi facilitada devido ao Setor de Olericultura da UFVJM ser localizado no Campus JK, que é a sede da maioria dos cursos de graduação em Diamantina. Consequentemente, os estudantes 
participavam das atividades desde o plantio até a época de colheita de cada hortaliça, em seus horários livres de aula, enquanto estavam no Campus.

No período de realização do projeto, os estudantes cultivaram abóbora menina, abóbora de tronco redondo, alface, alface roxa, beterraba, brócolis, cenoura, couve-flor, couve-folha, pimenta e rabanete. Os estudantes desenvolveram o próprio substrato para a produção de mudas de hortaliças em bandejas de isopor (Figura 3), cultivadas em ambiente protegido (estufas). O substrato foi formulado com duas partes do Composto Orgânico produzido no Setor de Compostagem da UFVJM, com uma parte de solo arenoso da própria horta, ambos peneirados a $8 \mathrm{~mm}$. Para cada três litros de substrato acrescentaram-se 40 gramas do fertilizante superfosfato simples granulado para a adequada nutrição das mudas. Adubação nitrogenada complementar das mudas foram realizadas quinzenalmente regando-se a planta com solução contendo 5 gramas de ureia por litro de água. No canteiro (Figura 3), as mudas foram cultivadas apenas com uso do composto orgânico, como fonte de nutrientes e irrigadas por aspersão convencional.

FIGURA 3 - MUDAS PRODUZIDAS EM BANDEJAS DE ISOPOR (ESQUERDA) E TRANSPLANTE PARA CANTEIRO COM COMPOSTO ORGÂNICO, NA HORTA UNIVERSITÁRIA (DIREITA), DIAMANTINA-MG.

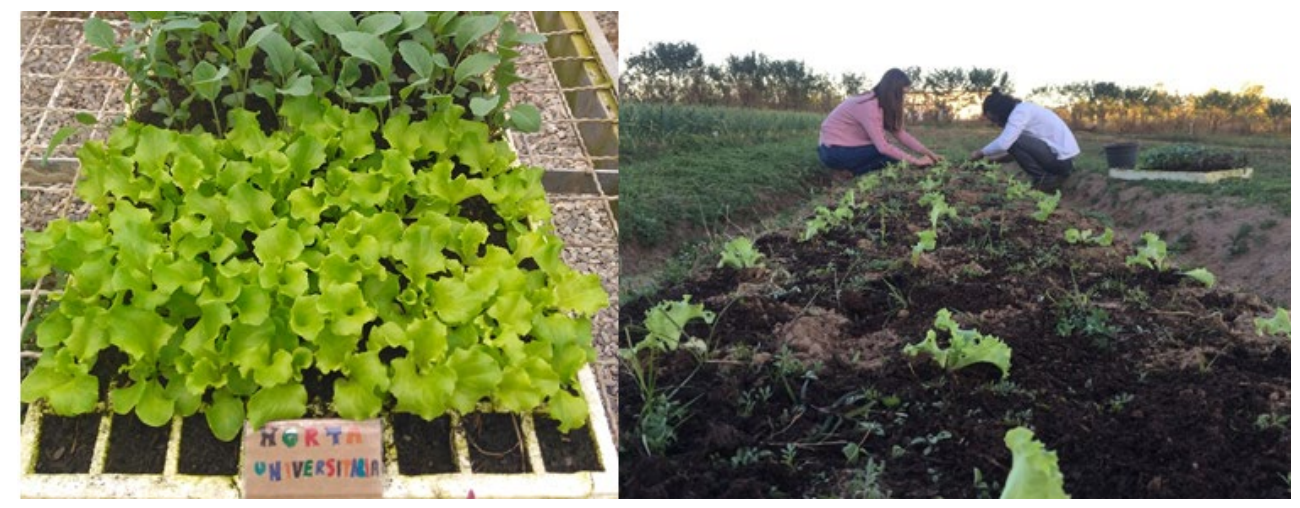

Fonte: ACERVo do Projeto Horta UniVERSITÁrIA, 2018.

A Figura 4 apresenta a autoavaliação dos estudantes, numa escala de 0 a 5 , onde zero caracterizaria um baixo envolvimento, interação e desempenho nas ações de extensão, enquanto cinco caracterizaria um excelente desempenho. Os estudantes classificaram o envolvimento no projeto durante o período de participação. Percentualmente, cerca de 37,5 \% classificaram o envolvimento como excelente (envolve-se em todas as atividades); $50 \%$ como boa 
(envolveu-se em grande parte das atividades) e apenas 12,5\% avaliou a sua participação como média (envolveu-se em parte das atividades). A nota média dos estudantes em relação ao envolvimento nas atividades, portanto, foi de 4,3 (Figura 4). Nesse sentido, pode-se inferir que o envolvimento dos alunos nas atividades do projeto foi um aspecto positivo no trabalho desenvolvido, contemplando as expectativas iniciais.

A maioria dos estudantes (62,5\%) consideraram que tiveram uma excelente interação na equipe ao longo do desenvolvimento das ações de extensão realizadas pelo projeto, sendo que a nota média da autoavaliação dos estudantes para esse parâmetro foi de 4,5 .

Figura 4 - AutoAVALIAÇÃo do ENVOLVIMENTO, INTERAÇÃo E DESEMPENHO DE CADA ESTUDANTE NO PROJETO DE EXTENSÃO, DiAMANTINA-MG.

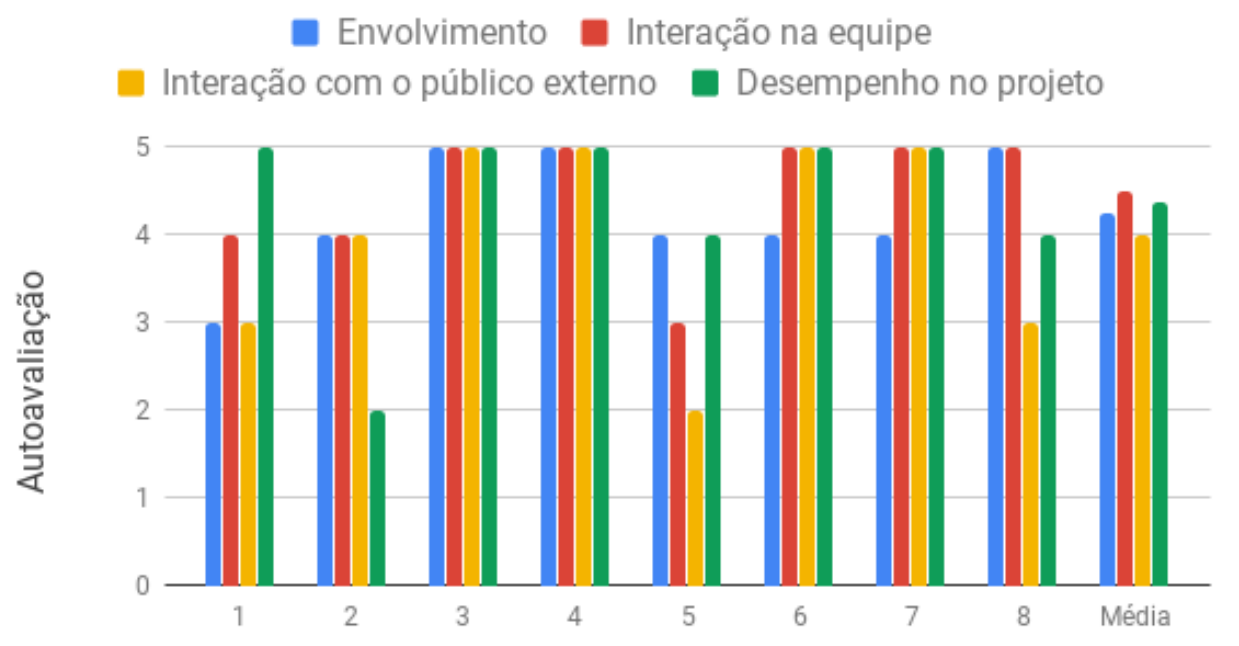

Estudantes

FontE: DADOS Do PROJETO, 2018, NúMEROS DE 1 A 8, NO EIXO HORIZONTAL REPRESENTAM CADA ESTUDANTE.

Por outro lado, a nota média referente a interação com o público externo caiu para 4,0 (Figura 4); considerada boa na escala de notas. Percentualmente, $50 \%$ dos estudantes consideraram que sua interação com o público externo nas ações de extensão como oficinas, criação de material didático e participação no estande da Semana de Ciência e Tecnologia foi excelente, enquanto 25 \% julgou que essa interação foi média e 12,5 \% achou que foi fraco nesse aspecto. $\mathrm{O}$ desempenho no projeto de modo geral foi avaliado positivamente, com nota média de 4,4 , sendo classificado como excelente e bom pela maioria dos estudantes. 
Em termos acadêmicos, pode-se observar que a participação dos estudantes nas ações do projeto de extensão melhorou seu desempenho nas disciplinas cursadas. Em relação às reprovações, três estudantes entraram no projeto sem reprovações e não foram reprovados em nenhuma disciplina cursada até o término do projeto. Outros três estudantes haviam entrado no projeto com uma reprovação cada. No decorrer do projeto, eles não conseguiram ser aprovados nessas disciplinas porque não se matricularam nelas novamente. No entanto, o fato positivo é que nenhum desses três estudantes foram reprovados em novas disciplinas. Portanto, somando esses três estudantes que tinham uma reprovação, mas não obtiveram novas reprovações e aqueles que já não apresentavam nenhuma reprovação e se mantiveram, percentualmente $75 \%$ dos estudantes participantes do projeto tiveram um bom desempenho acadêmico nas disciplinas cursadas concomitantemente as atividades de extensão desenvolvidas. Os outros dois estudantes integrantes do projeto tinham mais de uma reprovação ao entrarem na equipe e ao longo das ações de extensão obtiveram reprovação em uma nova disciplina cada um, sendo que um deles, por outro lado, conseguiu passar em uma das que havia sido reprovado anteriormente ao refazer a disciplina.

Em relação ao Coeficiente de Rendimento Acadêmico (CRA), a Figura 5, apresenta a evolução gráfica de cada estudante integrante do projeto de extensão. Nota-se que no início do projeto (CRA AP), apenas os estudantes 1 e 2 estavam abaixo da média de 60 pontos, representada pela linha amarela. No final do projeto (CRA DP), o estudante 1 melhorou significativamente seu desempenho acadêmico e evoluiu 11,3 pontos, mas ainda assim não foi suficiente para que superasse o nível médio, enquanto o estudante 2 evoluiu 12,1 pontos e chegou ao CRA de 69,9 pontos. De modo geral, apenas o estudante 7 teve uma queda no seu desempenho acadêmico ao final do projeto (CRA DP), mas mesmo assim, se manteve com 14,4 pontos acima da média. 
Figura 5 - Evolução do Coeficiente de Rendimento Acadêmico, Diamantina$-M G$.

$$
\text { - CRADP - CRAAP - CRA Médio }
$$

100

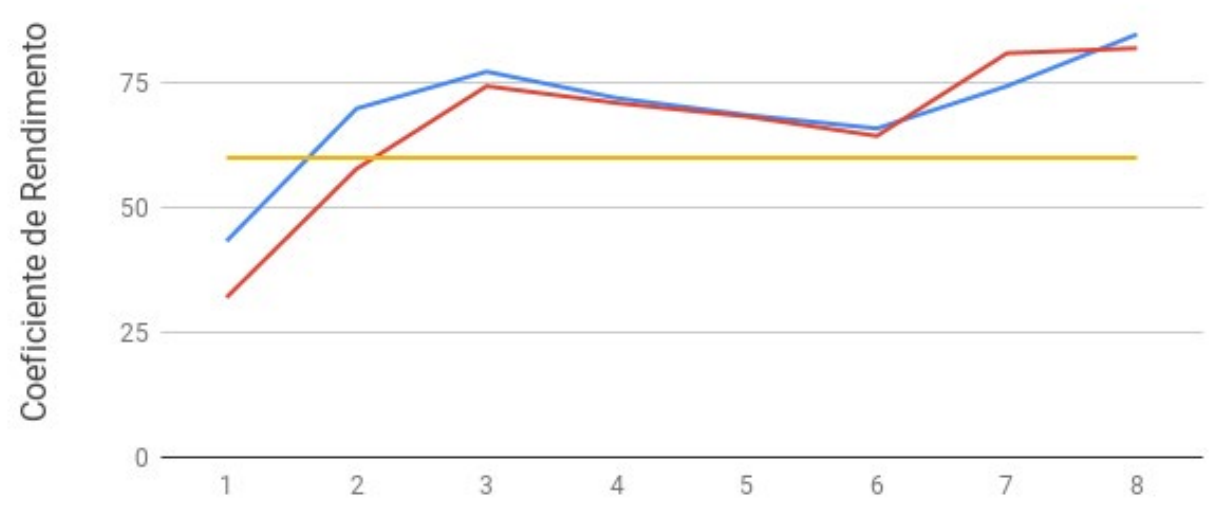

Estudantes

Fonte: DAdos do PRojeto, 2018, CRA AP - CoeficIENTE de Rendimento ACADÊMICO ANTES Do PRojeTO; CRA DP COEFICIENTE dE RENDIMENTO ACADÊMICO DEPOIS DO PROJETO; CRA MÉDIO-EXIGÊNCIA INSTITUCIONAL DE 60 PONTOS.

No final da participação desses estudantes no projeto de extensão "Horta Universitária", na autoavaliação, foi questionada qual a contribuição do projeto para a vida acadêmica-profissional ou pessoal deles, visando o bem estar que foi trabalhado no primeiro encontro. Os depoimentos foram os seguintes:

"Integrando-me ao projeto percebi que teria que otimizar meus horários e dessa forma estive mais disciplinado. Expandi conhecimentos e mesmo cursando disciplinas de áreas opostas, o projeto foi de grande soma; as atividades efetuadas em grupo me fizeram entender como é que funciona a dinâmica em equipe." (E.1.)

"Uma maneira de ocupar o tempo." (E.2.)

“Ajudou-me muito na hora de plantar, colher, fazer mudas em casa." (E.3.)

"O projeto me ensinou a ser mais tolerante, poi,s tudo na vida tem hora certa de plantio, bem como da colheita." (E.4.)

"O projeto ajudou na socialização com pessoas de outros cursos e motivou a adquirir conhecimento sobre diversas áreas." (E.5.)

"O projeto me ajudou na socialização com pessoas de outros cursos e motivou a adquirir conhecimento sobre diversas áreas." (E.6.) 
"O projeto me ajudou muito dentro do meio acadêmico em virtude de emitir certificado. Além disso, aprendi várias coisas sobre como plantar alfaces, cenouras, mexer com a terra, entre outros." (E.7.)

"Passei a dar mais valor a uma simples hortinha em casa." (E.8.)

\section{CONSIDERAÇÕES FINAIS}

Um dos resultados mais expressivos do trabalho, diz respeito ao envolvimento efetivo dos estudantes de diferentes cursos de graduação, constituindo-se em uma equipe bastante multidisciplinar que obteve uma melhora significativa no seu desempenho acadêmico, uma vez que a maioria dos estudantes integrantes do projeto não obtiveram novas reprovações (75\%) e elevaram o Coeficiente de Rendimento Acadêmico (87,5 \%).

A abertura de uma oportunidade para que estudantes dos diversos cursos de graduação da UFVJM venham a integrar algum tipo de projeto em âmbito universitário, mesmo como voluntário, além de cumprir com o dever constitucional da universidade referente a indissociabilidade do ensino, pesquisa e extensão, torna-se uma atividade motivadora e que contribui positivamente para a manutenção ou melhoria do rendimento acadêmico. Por sua vez, a melhoria no rendimento acadêmico, elimina um possível fator que levaria a evasão desse aluno do curso ou da instituição de ensino superior.

\section{REFERÊNCIAS}

ALVES, H. J.; BOOG, M. A. F. Comportamento alimentar em moradia estudantil: um espaço para a promoção da saúde. Rev. Saúde Pública, São Paulo, v. 41, n. 2, p. 197-204, 2007. Disponível em: http://dx.doi.org/10.1590/S0034-89102007000200005. Acesso em: 12 de fev. 2019.

AMORIM, E.M.; SABINO, G.F.T. A evasão discente nos cursos de graduação presencial dos Campi da UFVJM em Diamantina/MG e seus desdobramentos para a gestão. Diamantina: Universidade Federal dos Vales do Jequitinhonha e Mucuri (UFVJM), 2017. Disponível em: http://alas2017.easyplanners.info/opc/tl/6635_evandro_das_merces. Acesso em: 15 de mar. 2019.

CRIBB, S. L. P. Contribuições da educação ambiental e horta escolar na promoção de melhorias ao ensino, à saúde e ao ambiente. Ensino, Saúde e Ambiente, v. 3, n. 1, p. 
42-60, 2010. Disponível em: http://dx.doi.org/10.28998/rca.v15i0.3604. Acesso em: 12 de fev. 2019.

CUNHA, S. M.; CARILLO, D. M.. O processo de adaptação ao ensino superior e o rendimento acadêmico: adaptação e rendimento acadêmico. Psicologia Escolar e Educacional, v.9, n.2, 2005. Disponível em: http://dx.doi.org/10.1590/S1413-85572005000200004. Acesso em: 12 de fev. 2019.

FERNANDES, A. C. Cultivo orgânico: importância da horta orgânica. Florianópolis: EPAGRI, 2011. Disponível em: http://cultivehortaorganica.blogspot.com/2011/06/ importancia-da-horta-organica.html. Acesso em: 20 de abr. 2019.

FORPROEX - FÓRUM DE PRÓ-REITORE DE EXTENSÃO DAS UNIVERSIDADES PÚBLICAS BRASILEIRAS. Política Nacional de Extensão Universitária. Manaus: FORPROEX, 2012. Disponível em: http://www.unifal-mg.edu.br/extensao/files/image/ arquivos/2012-07-13-Politica-Nacional-de-Extensao.pdf. Acesso em: 15 de mar. 2019. HABERMAN, S., LUFFEY, D. Weighing in college students' diet and exercise behaviors. J. Am. Coll. Health, v. 46, n. 4, p.189-191, 1998. Disponível em: https://www.ncbi.nlm. nih.gov/pubmed/9519583. Acesso em: 11 de jan. 2019.

HORTA FSP-USP. Horta Comunitária USP - Quem Somos. Universidade federal de São Paulo. Disponível em: http://hortafspusp.blogspot.com.br/p/quem-somos.html. Acesso em: 15 mar. 2019.

MORGADO, F.S; SANTOS, M.A.A. A horta escolar na educação ambiental e alimentar: experiência do projeto horta viva nas escolas municipais de Florianópolis. Revista eletrônica de extensão da UFSC, v.5, n.6, p. 1-10, 2008. Disponível em: https://periodicos. ufsc.br/index.php/extensio/article/view/9531. Acesso em: 11 de jan. 2019.

MORITZ, S.C.; DA COSTA, M.M. Horta Comunitária Semeando Saúde. Revista de Saúde Pública de Florianópolis, v. 1, n. 1, p. 57-62, 2018. Disponível em: http://moodle. saude.pmf.sc.gov.br/revista/index.php/rspf/article/view/8. Acesso em 15 de mar. 2019. NAHAS, M. V., BARROS, M. V. G., FRANCALACCI, V., O Pentáculo do Bem Estar; Base Conceitual para Avaliação do Estilo de Vida de Indivíduos ou Grupos. Revista Brasileira de Atividade Física \& Saúde; v. 5, n. 2; abr./jun., 2000. Disponível em: http://rbafs.org. br/RBAFS/article/view/1002. Acesso em: 20 de jan. 2018.

SANTOS, J.T. Ações afirmativas e educação superior nas universidades brasileiras: um balanço crítico da produção. Rev. Bras. Estudos Pedagógicos, v. 93, n. 234, p. 401-422, 2012. Disponível em: http://rbep.inep.gov.br/index.php/rbep/article/view/447. Acesso em: 02 de abr. 2019.

SCHEIDEMANTEL, S. E.; KLEIN, R.; TEIXEIRA, L. I. A importância da extensão universitária: o projeto construir. Congresso Brasileiro de Extensão Universitária, 2. 2004. Disponível em: https://www.ufmg.br/congrext/Direitos/Direitos5.pdf. Acesso em: 20 abr. 2019. 
SOUSA, L.P., PORTES E. A. As propostas de políticas/ações afirmativas das universidades públicas e as políticas/ ações de permanência nos ordenamentos legais. Rev. Bras. Estudos Pedagógicos, v. 92, n. 232, p. 516-541, 2011. Disponível em: http://rbep.inep. gov.br/index.php/rbep/article/view/665. Acesso em 20 abr. 2019.

VAN DER HORST, K., OENEMA, A., FERREIRA, I., WENDEL-VOS, W., GISKES, K., VAN LENTHE, F., BRUG, J. A systematic review of environmental correlates of obesityrelated dietary behaviors in youth, Health Education Research, v. 22, n. 2, p. 203-206, abr. 2007. Disponível em: https://www.ncbi.nlm.nih.gov/pubmed/16861362. Acesso em: 18 mar. 2019. 